\title{
A common fixed point theorem for Reich type co-cyclic contraction in dislocated quasi - metric paces
}

\author{
Busha Sharbu, Alemayehu Geremew*, and Asfawosen Berhane \\ Department of Mathematics, Jimma University, Oromia, Ethiopia
}

\begin{abstract}
In this paper we proved the existence of coincidence and common fixed points for Reich type co-cyclic contraction in dislocated quasi-metric space and also, show the uniqueness of the common fixed point. Our work extends the main result in (Karapinar and Erhan, 2011). Examples are also provided in support of our results.
\end{abstract}

Keywords/Phrases: Dislocated quasi-metric space, coincidence points, common fixed point, Reich type co-cyclic contraction

DOI: http://dx.doi.org/10.4314/ejst.v10i2.1

\section{INTRODUCTION}

The Banach Contraction Principle is a very popular tool for solving existence problems in many branches of Mathematical Analysis and its applications. There are many generalizations of this fundamental theorem. Some of the generalizations weaken the contractive nature of the map; for example see (Kannan, 1968; Kannan, 1969; Jungck, 1976; Sessa, 1982; Kirk et al., 2003; Karapinar and Erhan, 2011), and others. In other generalizations the ambient space is weakened; see (Zeyada et al., 2005; Aage and Saluke, 2008; Abbas et al., 2011; Chaipunya et al., 2012; Zoto et al., 2012; Panthi et al., 2015). This celebrated theorem can be stated as follows.

Theorem 1.1 (Banach, 1922): Let $(X, d)$ be a complete metric space and $T$ be a mapping of $X$ into itself satisfying:

$d(T x, T y) \leq k d(x, y)$, for all $x, y \in X$,

where $k \in[0,1)$. Then, T has a unique fixed point $x^{*} \in X$.

Inequality (1.1) implies continuity of T. A natural question is whether we can find contractive conditions which will imply existence of a fixed point in a complete metric space but do not imply continuity.

\footnotetext{
*Corresponding author: alemg1972@gmail.com

(C) This is an Open Access article distributed under the terms of the Creative Commons Attribution License (http://creativecommons.org/licenses/CC BY4.0).
} 
Kirk et al. (2003) introduced cyclic contractions in metric spaces and investigated the existence of proximity points and fixed points for cyclic contraction mappings. Since then many results appeared in this field, see (Jungck and Rhoades, 1998; Hitzler and Seda, 2000; Kirk et al., 2003; Aage and Saluke, 2008; Aage and Saluke, 2008a; Kikkawa and Suzuki, 2008; Kohli et al., 2010; Karapinar and Erham, 2011; Chaipunya et al., 2012; Kumari et al., 2012; Zoto et al., 2012; Rahman and Sarwar, 2014).

Definition 1.2 (Kirk et al., 2003): A mapping $T: A \cup B \rightarrow A \cup B$ is called cyclic if $T(A) \subseteq B$ and $T(B) \subseteq A$, where $A, B$ are nonempty subsets of a metric space $(X, d)$.

Definition 1.3 (Kirk et al., 2003): A mapping $T: A \cup B \rightarrow A \cup B$ is called a cyclic contraction if there exists $k \in[0,1)$ such that

$d(T x, T y) \leq k d(x, y)$ for all $x \in A$ and $y \in B$.

The concept of quasi-metric spaces was introduced by Wilson (1931) as a generalization of metric spaces, and Hitzler and Seda (2000) introduced dislocated metric spaces as a generalization of metric spaces. Furthermore, Zeyada et al. (2005) generalized the results of Hitzler and Seda (2000) and introduced the concept of complete dislocated quasi metric space. Aage and Salunke $(2008,2008 \mathrm{a})$ derived some fixed point theorems in dislocated quasi metric spaces.

Jungck (1976) proved a common fixed point theorem for commuting maps by generalizing the Banach's fixed point theorem. The concept of the commutativity has been generalized in several ways. For this, Sessa (1982) has introduced the concept of weakly commuting mappings and Jungck (1986) initiated the concept of compatibility. When two mappings are commuting then they are compatible but not conversely. Jungck and Rhoades (1998) introduced the notion of weakly compatible mappings and showed that compatible maps are weakly compatible but not conversely. The study of common fixed point of mappings satisfying contractive type conditions has been a very active field of research activity.

Chaipunya (2012) introduced co-cyclic contractions as follows which is a guarantee for common fixed point theorem of a pair of self-mappings.

Definition 1.4 (Chaipunya, 2012): Let $T, f: A \cup B \rightarrow A \cup B$ be two self-mappings. $A \cup B$ is said to be cocyclic representation between $\mathrm{T}$ and $f$ if the following conditions are satisfied :

i. Both $A$ and $B$ are nonempty subsets of $A \cup B$,

ii. $T(A) \subset f(B)$ and $T(B) \subset f(A)$.

Karapinar and Erham (2011) introduced the following definition and established the theorem following it.

Definition 1.6 (Karapinar and Erham, 2011): Let A and B be non-empty subsets of a metric space (X, d). A 
cyclic map $T: A \cup B \rightarrow A \cup B$ is said to be Reich type cyclic contraction if:

$d(T x, T y) \leq a d(x, y)+b d(T x, x)+c d(T y, y)$ for all $x \in A$ and $y \in B$,

where $\mathrm{a}, \mathrm{b}, \mathrm{c}$ are non-negative real numbers satisfying $a+b+c<1$.

Theorem 1.7 (Karapinar and Erham, 2011): Let $A$ and $B$ be non-empty closed subsets of a complete metric space $(X, d)$ and $T: A \cup B \rightarrow A \cup B$ be a Reich type cyclic contraction. Then $T$ has a unique fixed point in $A \cap B$. Inspired and motivated by the result of Karapinar and Erhan (2011) in this paper, we prove the existence of coincidence points and common fixed points of a pair of self-mappings satisfying the conditions of Reich type co-cyclic contraction in dislocated quasi-metric space. Also, the uniqueness of the common fixed points has been shown. An example has been provided in support of our main result.

\section{PRELIMINARIES}

We recall the definition of complete metric space, quasi metric space, dislocated metric space, dislocated quasi metric space, the notion of convergence and other results that will be needed in the sequel.

Definition 2.1 (Zeyada et al., 2005): Let $X$ be a non-empty set. Suppose that the mapping d: $X \times X \rightarrow[0, \infty)$ satisfies the following conditions:

$$
\begin{aligned}
& \mathrm{d}_{1}: \mathrm{d}(\mathrm{x}, \mathrm{x})=0 \text {, for all } \mathrm{x} \in \mathrm{X} . \\
& d_{2}: \mathrm{d}(\mathrm{x}, \mathrm{y})=\mathrm{d}(\mathrm{y}, \mathrm{x})=0 \text { implies } \mathrm{x}=\mathrm{y} . \\
& \mathrm{d}_{3}: \mathrm{d}(\mathrm{x}, \mathrm{y})=\mathrm{d}(\mathrm{y}, \mathrm{x}) \text {, for all } \mathrm{x}, \mathrm{y} \in \mathrm{X} . \\
& d_{4}: d(x, y) \leq d(x, z)+d(z, y), \text { for all } \mathrm{x}, \mathrm{y}, \mathrm{z} \in \mathrm{X} .
\end{aligned}
$$

Then, the pair $(X, d)$ is called metric space. If $d$ satisfies $d_{1}, d_{2}$ and $d_{4}$, then $(X, d)$ is called quasi metric space (Wilson, 1931). If $d$ satisfies $d_{2}, d_{3}$ and $d_{4}$, then $(X, d)$ is called dislocated metric space (Hitzler and Seda, 2000). If $d$ satisfies $d_{2}$ and $d_{4}$, then (X, d) is called dislocated quasi metric space and we denoted it by dq-metric space (Zeyada et al., 2005).

Here we note that every metric space are quasi metric space, dislocated metric space and dislocated quasi metric space but the converse is not necessarily true and every dislocated metric space are dislocated quasi metric space but the converse is not always true (Zeyada et al., 2005).

Definition 2.2 (Zeyada et al., 2005): A sequence $\left\{x_{n}\right\}$ in a dq-metric space $(X, d)$ is called Cauchy sequence if for all $\varepsilon>0, \exists n_{\circ} \in N$ such that for $m, n \geq n_{o}$, we have

$$
d\left(x_{m}, x_{n}\right)<\varepsilon \text { and } d\left(x_{n}, x_{m}\right)<\varepsilon
$$


Definition 2.3 (Zeyada et al., 2005): A sequence $\left\{x_{n}\right\}$ in a dq-metric space $(X, d)$ converges with respect to dq, if there exists $x$ in $X$, such that $\lim _{n \rightarrow \infty} d\left(x_{n}, x\right)=\lim _{n \rightarrow \infty} d\left(x, x_{n}\right)=0$. In this case, $x$ is called a dq limit of $\left\{x_{n}\right\}$ and we write as $x_{n} \rightarrow x$.

Definition 2.4 (Zeyada et al., 2005): A dq-metric space $(X, d)$ is called complete if every Cauchy sequence in it is convergent in $X$ with respect to dq.

Lemma 2.5 (Zeyada et al., 2005): Limits in a dq-metric space are unique.

Definition 2.6 (Zeyada et al., 2005): Let $(X, d)$ be a dq-metric space. A mapping $T: X \rightarrow X$ is called contraction if there exists $k \in[0,1)$ such that $d(T x, T y) \leq k d(x, y)$ for all $x, y$ in $X$

Theorem 2.7 (Zeyada et al., 2005): Let $(X, d)$ be a complete dq-metric space and let $T: X \rightarrow X$ be a contraction mapping. Then, $T$ has a unique fixed point.

Definition 2.8 (Kirk et al., 2003): Let $A$ and $B$ be non-empty subset of a dq-metric space $(X, d)$ and $T: A U B \rightarrow A U B$ be a self -map. $T$ is said to be dq-cyclic map if and only if $T(A) \subseteq B$ and $T(B) \subseteq A$ and is said to be dq-cyclic contraction if there exists $k \in[0,1)$ such that $d(T x, T y) \leq k d(x, y)$ for all $x$ in $A$ and $y$ in $B$.

Definition 2.9 (Jungck and Rhoades, 1998): Let X be a non-empty set. Two self-maps $T, f: X \rightarrow X$ are said to be

i. Commuting if $T f x=f T x$ for all $x$ in $X$. If $T x=f x$ for some $x$ in $X$, then $x$ is called coincidence point of $T$ and $f$. We denote the set of coincidence points of $T$ and $f$ by $C(T, f)$.

ii. Weakly compatible if they commute at their coincidence points .i.e. if $u$ in $X$ such that $T u=f u, \operatorname{then} T f u=f T u$.

Definition 2.10 (Jungck and Rhoades, 1998): Let, $f: X \rightarrow X$. If $z=T w=f w$, then $\mathrm{z}$ is called point of coincidence of $f$ and $T$; and $\mathrm{w}$ is called coincidence point of $f$ and $T$. If $z=w$, then $z$ is called a common fixed point of $T$ and $f$.

Example 2.1 Let $X=\left[\frac{1}{2}, 1\right]$ be equipped with a dq-metric $d(x, y)=|x-y|$.

Define $T, f: X \rightarrow X$ by $T(x)=\left\{\begin{array}{l}1, \frac{1}{2} \leq x<\frac{2}{3} \\ x, \frac{2}{3} \leq x \leq 1\end{array}\right.$ 
and

$$
f(x)= \begin{cases}\frac{1}{2}, & \frac{1}{2} \leq x<\frac{2}{3} \\ 1-\frac{1}{2} x, & \frac{2}{3} \leq x \leq 1\end{cases}
$$

Then for any $x$ in $C(T, f)=\left\{\frac{2}{3}\right\}, f T x=T f x$, showing that $\mathrm{f}$, $\mathrm{T}$ are weakly compatible maps on $X$ and $\mathrm{x}=\frac{2}{3}$ is a common fixed point of $\mathrm{T}$ and $\mathrm{f} . "$

Example 2.2 (Jungck and Rhoades, 1998): Let $X=R$ and define $\mathrm{T}, \mathrm{f}: \mathrm{X} \rightarrow \mathrm{X}$ by $T x=x^{2}$ and $f x=\frac{x}{3}$ for $x$ in $X$. Hence, 0 and $1 / 3$ are two coincidence points of $f$ and $T$. Note that $f$ and $T$ commute at 0 , i.e., $f T(0)=T f(0)=0$ but $f T\left(\frac{1}{3}\right)=\frac{1}{27}$ and $T f\left(\frac{1}{3}\right)=\frac{1}{81}$ and so $f$ and $T$ are not weakly compatible mappings on $X$.

Next we state and prove the main result of this paper.

\section{MAIN RESULT}

Definition 3.1: Let A and B be non-empty subsets of a dislocated quasi metric space(X,d). The selfmap $T: X \rightarrow X$ is said to be a dq-Reich type co-cyclic contraction if there exists a selfmap $f: X \rightarrow X$ such that

i. $\mathrm{X}=\mathrm{AUB}$ is a co-cyclic representation of $\mathrm{X}$ between $\mathrm{T}$ and $\mathrm{f}$.

ii. $d(T x, T y) \leq a d(f x, f y)+b d(T x, f x)+c d(T y$, fy $)$ for all $x \in A$ and $y \in B$,

where $\mathrm{a}, \mathrm{b}, \mathrm{c}$ are nonnegative numbers such that $\mathrm{a}+\mathrm{b}+\mathrm{c}<1$.

Remark: In Definition 3.1(ii), if $\mathrm{b}=\mathrm{c}=0$, the pair of maps T,f : AUB $\rightarrow$ AUB $\quad$ is said to be $(T, f)-\mathrm{dq}$ co-cyclic contraction and if $\mathrm{a}=0$, we call them $(T, f)$-dq-Kannan type co-cyclic contraction.

Theorem 3.2: Let $\mathrm{A}$ and $\mathrm{B}$ be non-empty subsets of a complete dislocated quasi dq- metric space $(X, d)$. Let $T, f: A U B \rightarrow A U B$ be a $(T, f)$ dq-Reich type co-cyclic contraction. If $f: X \rightarrow X$ is injective and $f(A)$ and $f(B)$ are closed subsets of $X$, where $T$ and $f$ are weakly compatible mappings, then $T$ and $f$ have a unique common fixed point in $f(A) \cap f(B)$.

Proof: Let $x_{0} \in A$ (fix), $T(A) \subseteq f(B)$, there exist $x_{1} \in B$ such that $T x_{0}=f x_{1}=y_{0}$ (say). Since $x_{1} \in B$, there exist $x_{2} \in A$ such that $T x_{1}=f x_{2}=y_{1}$ (say).

On continuing this procedure inductively, we get a sequence $\left\{y_{\mathrm{n}}\right\}$ in $X$ such that $y_{n}=T x_{n}=f x_{n+1}$ for each $n=0,1,2, \cdots$, where $\left\{x_{2 n}\right\} \subseteq A$ and $\left\{x_{2 n-1}\right\} \subseteq B$ for each $n=1,2, \cdots$. 
Now, we want to show that the sequence $\left\{y_{n}\right\}$ is a Cauchy sequence in $X$.

Now consider

$$
\begin{aligned}
d\left(y_{2}, y_{1}\right)=d\left(T x_{2}, T x_{1}\right) \leq & a d\left(f x_{2}, f x_{1}\right)+b d\left(T x_{2}, f x_{2}\right)+c d\left(T x_{1}, f x_{1}\right) \\
& =a d\left(y_{1}, y_{0}\right)+b d\left(y_{2}, y_{1}\right)+c d\left(y_{1}, y_{0}\right) .
\end{aligned}
$$

This implies,

$$
\begin{aligned}
& (1-b) d\left(y_{2}, y_{1}\right) \leq(a+c) d\left(y_{1}, y_{0}\right) \\
& \text { and thus we obtain } \mathrm{d}\left(\mathrm{y}_{2}, \mathrm{y}_{1}\right) \leq\left[\frac{\mathrm{a}+\mathrm{c}}{1-\mathrm{b}}\right] d\left(y_{1}, y_{0}\right),
\end{aligned}
$$

where $\frac{a+c}{1-b}<1$. Let $k=\left[\frac{a+c}{1-b}\right]$. Then $0<k<1$.

So, (3.1) becomes

$$
\begin{gathered}
\qquad d\left(y_{2}, y_{1}\right) \leq k d\left(y_{1}, y_{0}\right) \\
\text { And hence we have } d\left(y_{2}, y_{1}\right) \leq k \alpha,
\end{gathered}
$$

where $\alpha=\max \left\{d\left(y_{1}, y_{0}\right), d\left(y_{0}, y_{1}\right)\right\}$.

Now again,

$$
\begin{aligned}
d\left(y_{1}, y_{2}\right)=d\left(T x_{1}, T x_{2}\right) & \leq a d\left(f x_{1}, f x_{2}\right)+b d\left(T x_{1}, f x_{1}\right)+c d\left(T x_{2}, f x_{2}\right) \\
& =a d\left(y_{0}, y_{1}\right)+\mathrm{b} d\left(y_{1}, y_{0}\right)+c d\left(y_{2}, y_{1}\right) .
\end{aligned}
$$

Using (3.1) in (3.3), we obtain,

$$
\begin{aligned}
d\left(y_{1}, y_{2}\right) & \leq a d\left(y_{0}, y_{1}\right)+\mathrm{b} d\left(y_{1}, y_{0}\right)+\mathrm{c} \frac{(\mathrm{a}+\mathrm{c})}{1-b} d\left(y_{1}, y_{0}\right) \\
& =a d\left(y_{0}, y_{1}\right)+\left[b+c \frac{(\mathrm{a}+\mathrm{c})}{1-b}\right] d\left(y_{1}, y_{0}\right) \\
& \leq\left[a+b+c \frac{(\mathrm{a}+\mathrm{c})}{1-b}\right] \alpha \quad(\text { from }(3.2)) \\
& =\left[\frac{a-a b+b-b^{2}+c(a+c)}{(1-b)}\right] \alpha \\
& \leq\left[\frac{a-a b+b-b^{2}+c(1-b)}{(1-b)}\right] \alpha \quad(\text { since } \mathrm{a}+\mathrm{c}<1-\mathrm{b}) \\
& =\left[\frac{a+c+b(1-b)-b(a+c)}{(1-b)}\right] \alpha \\
& \leq\left[\frac{a+c+b(1-b)-b(1-b)}{(1-b)}\right] \alpha \quad(\text { since } \mathrm{a}+\mathrm{c}<1-\mathrm{b}) \\
& =\left[\frac{a+c}{1-b}\right] \alpha .
\end{aligned}
$$


This implies that

$$
d\left(y_{1}, y_{2}\right) \leq\left[\frac{a+c}{1-b}\right] \alpha=\mathrm{k} \alpha .
$$

Thus,

$$
d\left(y_{1}, y_{2}\right) \leq k \alpha .
$$

Similarly,

$$
d\left(y_{3}, y_{2}\right) \leq k d\left(y_{2}, y_{1}\right) \leq k^{2} \alpha .
$$

and

$$
d\left(y_{2}, y_{3}\right) \leq k^{2} \alpha
$$

Inductively, for each $n \in \mathbb{N}$, we have

$$
d\left(y_{n+1}, y_{n}\right) \leq k^{n} \alpha,
$$

and

$$
d\left(y_{n}, y_{n+1}\right) \leq k^{n} \alpha .
$$

Letting $n \rightarrow \infty$ in (3.7) and (3.8), we obtain

$$
d\left(y_{n+1}, y_{n}\right) \rightarrow 0,
$$

and

$$
d\left(y_{n}, y_{n+1}\right) \rightarrow 0 \text {. }
$$

Now let $n, m \in \mathbb{N}$, with $m>n$. By using the triangular inequality, we have

$$
\begin{aligned}
d\left(y_{m}, y_{n}\right) & =d\left(T x_{m}, T x_{n}\right) \leq d\left(T x_{n}, T x_{n+1}\right)+d\left(T x_{n+1}, T x_{n}\right) \\
d\left(y_{m}, y_{n}\right) & =d\left(T x_{m}, T x_{n}\right) \leq d\left(T x_{n}, T x_{n+1}\right)+d\left(T x_{n+1}, T x_{n}\right) \\
& \leq d\left(T x_{m}, T x_{n+2}\right)+d\left(T x_{n+2}, T x_{n+1}\right)+d\left(T x_{n+1}, T x_{n}\right) \\
& \leq d\left(T x_{m}, T x_{n+2}\right)+d\left(T x_{n+2}, T x_{n+1}\right)+d\left(T x_{n+1}, T x_{n}\right) \\
& \ldots \ldots \ldots \ldots \ldots \ldots \ldots \ldots \ldots \ldots \ldots \ldots \ldots \ldots \ldots \ldots \ldots \ldots \\
& \leq d\left(T x_{m}, T x_{m-1}\right)+d\left(T x_{m-1}, T x_{m-2}\right)+\ldots \ldots+d\left(T x_{n+1}, T x_{n}\right) \\
& \leq d\left(T x_{m}, T x_{m-1}\right)+d\left(T x_{m-1}, T x_{m-2}\right)+\ldots \ldots+d\left(T x_{n+1}, T x_{n}\right) \\
& \leq k^{m-1} \alpha+k^{m-2} \alpha+\ldots+k^{n} \alpha \leq k^{m-1} \alpha+k^{m-2} \alpha+\ldots+k^{n} \alpha \\
& \leq\left(k^{m-1}+k^{m-2}+\ldots+k^{n}\right) \alpha \leq\left(k^{m-1}+k^{m-2}+\ldots+k^{n}\right) \alpha \\
& \leq k^{n}\left(k^{m-n-1}+k^{m-n-2}+\ldots+k+1\right) \alpha \\
& \leq k^{n}\left(k^{m-n-1}+k^{m-n-2}+\ldots+k+1\right) \alpha \\
& =k^{n}\left(\sum_{i=0}^{m-n-1} k^{i}\right) \alpha
\end{aligned}
$$




$$
\begin{aligned}
& \leq\left(k^{n} \sum_{i=0}^{\infty} k^{i}\right) \alpha \\
& =k^{n} \frac{\alpha}{1-k^{*}}
\end{aligned}
$$

This implies,

$$
d\left(y_{m}, y_{n}\right) \leq k^{n} \frac{\alpha}{1-k} .
$$

Taking $n \rightarrow \infty$ in (3.11), we obtain $d\left(y_{m}, y_{n}\right) \rightarrow 0$.

Similarly, let $n, m \in N$ with $m>n$. By a similar procedure, we obtain

$$
d\left(y_{n}, y_{m}\right)=d\left(T x_{n}, T x_{m}\right) \leq k^{n} \frac{\alpha}{1-k} \text {. }
$$

Taking $\mathrm{n} \rightarrow \infty$ in (3.12), we obtain $d\left(y_{n}, y_{m}\right) \rightarrow 0$.

Thus, $\left\{y_{n}\right\}$ is a Cauchy sequence in $\mathrm{X}$.

Since $X$ is complete, there exists $z$ in $X$ such that $\lim _{n \rightarrow \infty} y_{n}=z$.

Thus, $\lim _{n \rightarrow \infty} T x_{n}=\lim _{n \rightarrow \infty} f x_{n+1}=\mathrm{z}$

Since the sequence $\left\{y_{n}\right\}$ as $n \rightarrow \infty$ converges to $z$, the subsequence $\left\{y_{2 n}\right\}$, where $y_{2 n}=T x_{2 n}$, for each $\mathrm{n}=0,1,2, \cdots$, converges to z. But, $\left\{y_{2 n}\right\} \subseteq T(A) \subseteq f(B) \subseteq T(A) \subseteq f(B)$. Since $f(B)$ is closed, $z \in f(B)$. So, there exists $u_{1} \in B$ such that $f u_{1}=z$.

Also, the subsequence $\left\{y_{2 n-1}\right\}$, where $y_{2 n-1}=T x_{2 n-1}$ for each $n=1,2, \cdots$ converges to $z$.

But, $\left\{y_{2 n-1}\right\} \subseteq T(B) \subseteq f(A)$ for each $\mathrm{n}=1,2, \cdots$ since $f(A)$ is closed, $z \in f(A)$. So, there exists $u_{2} \in A$ such that $f u_{2}=z$. Hence $f(A) \cap f(B) \neq \phi$ and $f u_{1}=f u_{2}=z$.

Since $f: X \rightarrow X$ is injective map, we get $u_{1}=u_{2}=u$ (say).

Hence $u \in A \cap B$ such that $z=f u$.

Now, we show that $d(z, z)=0$.

Consider,

$$
d\left(T x_{2 n}, T x_{2 n-1}\right) \leq a d\left(f x_{2 n}, f x_{2 n-1}\right)+b d\left(T x_{2 n}, f x_{2 n}\right)+c d\left(T x_{2 n-1}, f x_{2 n-1}\right) .
$$

Taking $n \rightarrow \infty$, we obtain

$$
d(z, z) \leq a d(z, z)+b d(z, z)+c d(z, z) .
$$

This implies

$$
d(z, z)=0 .
$$

Now, for each $n=0,1,2, \cdots$, we have

$$
d\left(T u, y_{2 n-1}\right)=\mathrm{d}\left(T u, T x_{2 n-1}\right)
$$




$$
\leq a d\left(f u, f x_{2 n-1}\right)+b d(T u, f u)+c d\left(T x_{2 n-1}, f x_{2 n-1}\right) .
$$

Taking $n \rightarrow \infty$, we obtain

$$
\begin{aligned}
& d(T u, z) \leq a d(f u, z)+b d(T u, f u)+c d(z, z) . \\
& d(T u, z) \leq a d(f u, z)+b d(T u, f u)+c d(z, z) .
\end{aligned}
$$

This implies

$$
(1-b) d(T u, z) \leq 0 .
$$

This implies

$$
d(T u, z)=0 .
$$

Similarly, for each $n=0,1,2, \cdots$, we obtain

$$
\begin{aligned}
d\left(y_{2 n-1}, T u\right)= & d\left(T x_{2 n-1}, T u\right) \\
& \leq \mathrm{ad}\left(f x_{2 n-1}, f u\right)+\mathrm{bd}\left(T x_{2 n-1}, f x_{2 n-1}\right)+\mathrm{cd}(T u, f u) .
\end{aligned}
$$

Taking $n \rightarrow \infty$, we obtain

$$
\begin{array}{r}
d(z, T u) \leq a d(z, z)+b d(z, z)+c d(T u, z) . \\
d(z, T u) \leq a d(z, z)+b d(z, z)+c d(T u, z) .
\end{array}
$$

This implies

$$
d(z, T u)=0 .
$$

So, from (3.14) and (3.15), we get $T u=z$.

Hence, $T u=z=f u$.

Therefore, $u$ is a coincidence point of $T$ and $f$, and $T u=f u$, we have hence $C(T, f)$ is a non-empty set.

Since $\mathrm{T}$ and $\mathrm{f}$ are weakly compatible mappings, and $T f u=f T u$, whenever $T u=f u$.

So, $T z=T f u=f T u=f z$.

Now, we claim that $z=T z=f z$.

Consider,

$$
\begin{array}{r}
d(T z, T z) \leq a d(f z, f z)+b d(T z, f z)+c d(T z, f z) \\
=a d(T z, T z)+b d(T z, T z)+c d(T z, T z) . \\
=a d(T z, T z)+b d(T z, T z)+c d(T z, T z) .
\end{array}
$$

This implies that 


$$
d(T z, T z)=0 .
$$

So,

$$
\begin{aligned}
d(T z, z) & =d(T z, T u) \leq a d(f z, f u)+b d(T z, f z)+c d(T u, f u) \\
& =d(T z, T u) \leq a d(T z, z)+b d(T z, T z)+c d(z, z) . \\
& =d(T z, T u) \leq a d(T z, z)+b d(T z, T z)+c d(z, z) .
\end{aligned}
$$

This implies $(1-a) d(T z, z) \leq 0$.

From (3.13) and (3.16), we obtain

$$
d(T z, z)=0 .
$$

Similarly,

$$
\begin{gathered}
d(z, T z)=d(T u, T z) \leq a d(f u, f z)+b d(T u, f u)+c d(T z, f z) \\
d(z, T z)=d(T u, T z) \leq a d(f u, f z)+b d(T u, f u)+c d(T z, f z) \\
=a d(z, T z)+b d(z, z)+c d(T z, T z)
\end{gathered}
$$

Again from (3.13) and (3.16), we obtain

$$
(1-a) d(z, T z) \leq 0 \text {, }
$$

and hence

$$
d(z, T z)=0 .
$$

From (3.17) and (3.18), we obtain $T z=z$.

Since $T z=f z$, we obtain

$$
T z=f z=z .
$$

Therefore, $\mathrm{z}$ is a common fixed point of $T$ and $f$ in $X$.

Now, we show the uniqueness of $z$.

Let $\mathrm{w} \in X \in X$ be another common fixed point of $T$ and $f$. Then we have

$$
\begin{aligned}
& d(w, w)=d(T w, T w) \leq a d(f w, f w)+b d(T w, f z)+c d(T w, f w) \\
& =a d(w, w)+b d(w, w)+c d(w, w) \\
& =(a+b+c) d(w, w) .
\end{aligned}
$$

This gives

$(1-a-b-c) d(w, w) \leq 0$,

which implies $d(w, w)=0$ 
Consequently, we obtain

$$
\begin{aligned}
d(z, w)=d(T z, T w) & \leq a d(f z, f w)+b d(T z, f z)+c d(T w, f w) \\
& =a d(z, w)+b d(z, z)+c d(w, w) \\
& =a d(z, w) .
\end{aligned}
$$

Thus we obtain

$$
(1-a) d(z, w) \leq 0 .
$$

This implies

$$
d(z, w)=0 .
$$

Similarly,

$$
\begin{aligned}
& d(w, z)=d(T w, T z) \leq a d(f w, f z)+b d(T w, f w)+c d(T z, f z) \\
& =a d(w, z)+b d(w, w)+c d(z, z) \\
& =a d(w, z) . \\
& \Rightarrow(1-a) d(w, z) \leq 0 .
\end{aligned}
$$

This implies $d(w, z)=0$

Thus, from (3.19) and (3.20) we obtain $z=w$.

Therefore, $z$ is a unique common fixed point of $T$ and $f$ in $X$.

Corollary 3.2: Let A and B be non-empty subsets of a complete dislocated quasi (dq)-metric space $(X, d)$. Let $T, f: A U B \rightarrow A U B$ be a $(T, f)$ dq co-cyclic contraction. If $f: X \rightarrow X$ is injective and $f(A)$ and $f(B)$ are closed subsets of $X$, where $T$ and $f$ are weakly compatible mappings, then $T$ and $f$ have a unique common fixed point in $f(A) \cap f(B)$.

Proof: Taking $b=0$ and $c=0$, the proof follows from Theorem 3.2.

Corollary 3.3: Let $A$ and $B$ be a non-empty subsets of a complete dislocated quasi dq-metric space $(X, d)$. Let $T, f: A U B \rightarrow A U B$ be a $(T, f)$ Kannan type dq co-cyclic contraction. If $f: X \rightarrow X$ is injective and $f(A)$ and $f(B)$ are closed subsets of $X$, where $T$ and $f$ are weakly compatible mappings, then $T$ and $f$ have a unique common fixed point in $f(A) \cap f(B)$.

Proof: Taking $a=0$ and $b=c$, the proof follows from Theorem 3.2.

Remark 1: If $f: A U B \rightarrow A U B$ is the identity mapping, Theorem 3.2 become Theorem 1.7. This shows that Theorem 3.2 is an extension of Theorem 1.7.

The following is an example in support of Theorem 3.2.

Example 3.4: . Let $X=\mathbb{R}, A=(-\infty, 2]$ and $B=[0, \infty)$. 
Let $d: X \times X \rightarrow[0, \infty)$ be a dislocated quasi metric space defined by

$$
d(x, y)=|x-y|+|y| \text { for all } x, y \text { in } X .
$$

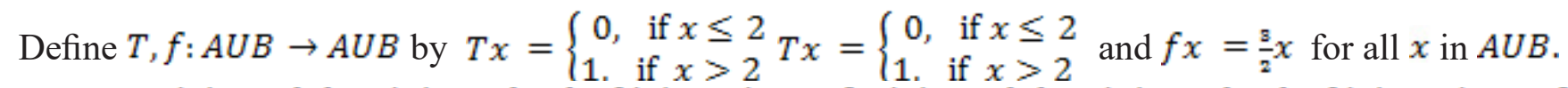
Then $T(A)=\{0\}, T(B)=\{0,1\}, f(A)=(-\infty, 3] T(A)=\{0\}, T(B)=\{0,1\}, f(A)=(-\infty, 3]$ and $f(B)=[0, \infty)$.

This implies $\mathrm{T}(A) \subseteq f(B)$ and $T(B) \subseteq f(A)$. Hence, $X=A U B$ is a co-cyclic representation with respect to the pair $(T, f)$ and collection $\{A, B\}$.

Now we check the inequality of the conditions of Reich type contraction by considering the following cases.

Case 1: Let $x \in A$ and $y \in B$.

We shall consider the following two sub cases $x \in A, y \in[0,2]$ and $x \in A, y>2$.

If $x \in A$ and $y \in[0,2]$, the inequality clearly holds.

If $x \in A$ and $y>2$, we have

$$
\begin{aligned}
& d(T x, T y)=|T x-T y|+|T y|=2 ; \\
& d(f x, f y)=|f x-f y|+|f y|=3 y-\frac{3}{2} x ; \\
& d(T x, f x)=|T x-f x|+|f x|=\left|0-\frac{3}{2} x\right|+\left|\frac{3}{2} x\right|=3|x| ; \\
& d(T x, f x)=|T x-f x|+|f x|=\left|0-\frac{3}{2} x\right|+\left|\frac{3}{2} x\right|=3|x| ; \text { and } \\
& d(T y, f y)=|T y-f y|+|f y|=\left|1-\frac{3}{2} y\right|+\left|\frac{3}{2} y\right|=3 y-1 .
\end{aligned}
$$

So, if we choose $a=\frac{1}{5}, b=\frac{1}{5}$ and $c=\frac{2}{5}$, we have

$$
\frac{2}{5} d(T y, f y)=\frac{2}{5}(3 y-1) \geq \frac{2}{5}(5)=2 \forall y>2 .
$$

This implies

$$
d(T x, T y) \leq \frac{1}{5} d(f x, f y)+\frac{1}{5} d(T x, f x)+\frac{2}{5} d(T y, f y) \text { for all } x \in A \text {, and } y>2 .
$$

Case 2: Let $x \in B$ and $y \in A$.

Here also we consider the following two sub-cases, i.e., $x \in[0,2]$ and $y \in A$; and $x>2$ and $y \in A$. If $x \in[0,2]$ and $y \in A$, the contraction clearly holds.

If $x>2$ and $y \in A$.Then

$$
\begin{aligned}
& d(T x, T y)=|T x-T y|+|T y|=1 \\
& d(f x, f y)=|f x-f y|+|f y|=\left|\frac{3}{2} x-\frac{3}{2} y\right|+\left|\frac{3}{2} y\right|=\frac{3}{2}[|x-y|+|y|] \\
& d(T x, f x)=|T x-f x|+|f x|=\left|1-\frac{3}{2} x\right|+\left|\frac{3}{2} x\right|=3 x-1 ; \text { and } \\
& d(T y, f y)=|T y-f y|+|f y|=\left|0-\frac{3}{2} y\right|+\left|\frac{3}{2} y\right|=3|y|
\end{aligned}
$$


Now, if we choose $a=\frac{1}{5}, b=\frac{1}{5}$ and $c=\frac{2}{5}$, we have

$$
\frac{1}{5} d(T x, f x)=\frac{1}{5}(3 x-1) \geq \frac{1}{5}(5)=1 \text { for all } \mathrm{x}>2 .
$$

This implies

$$
d(T x, T y) \leq \frac{1}{5} d(f x, f y)+\frac{1}{5} d(T x, f x)+\frac{2}{5} d(T y, f y) \text { for all } x>2 \text { and } y \in A .
$$

Hence $T$ and $f$ satisfy all conditions of our theorem. Moreover, 0 is a unique common fixed point of $T$ and $f$ in $f(A) \cap f(B)$.

\section{CONCLUSION}

Karapinar and Erhan (2011) established the existence of fixed point for mapping satisfying the Reich type cyclic contraction in a complete metric space. In this paper, we proved the existence of coincidence points and a unique common fixed point of Reich type co-cyclic contraction defined in dislocated quasi-metric space. We have supported the main result of this research work by example. Our work extends the main result in Karapinar and Erhan (2011).

\section{ACKNOWLEDGMENTS}

The first author acknowledges College of Natural Science, Jimma University for funding this research work during his MSc study.

\section{REFERENCES}

Aage, C.T and Salunke, J.N. (2008). Some results of fixed point theorem in dislocated quasi metric space. Bulletin of Marathadawa Mathematical Society 9: 1-5.

Aage, C.T and Salunke, J.N. (2008a). The results of fixed points in dislocated and dislocated quasi metric space. Applied Mathematical Sciences 2: 2941-2948.

Abbas, M., Nazir, T and Radenovic, S. (2011). Common fixed points of four maps in partially ordered metric spaces. Applied Mathematics Letters 24: 1520-1526.

Abbas, M., Manuel, D.S and Nazir, T. (2015). Common fixed points of generalized rational type co-cyclic mappings in multiplicative metric spaces. Discrete Dynamics in Nature and Society http://dx.doi. org/10.1155/2015/532725.

Banach, S. (1922): Surles operations densles ensembles abstraits et leurapplictionanx equations integrals. Fundamenta Mathematicae 3(1):133-181.

Chaipunya, P., Cho, Y.J., Sintunavarat, W and Kumam, P. (2012). Fixed point and common fixed point theorems for cyclic Quasi-contractions in Metric and Ultra metric spaces, Advances in Pure Mathematics 2: 401-407.

Hitzler, P and Seda, A. (2000). Dislocated topologies. Journal of Electrical Engineering 51: 3-7. 
Isufati, A. (2010). Fixed point theorem in dislocated quasi metric spaces. Applied Mathematical Sciences 4: 217-223.

Jungck, G. (1976). Commuting mappings and fixed points. American Mathematical Monthly 83: 261-263. Jungck, G. (1986). Compatible mappings and common fixed points. International Journal of Mathematics and Mathematical Sciences 9(4): 771-779.

Jungck, G and Rhoades, B.E. (1998). Fixed point for set valued functions without continuity. Indian Journal of Pure and Applied Mathematics 29 (3): 227-238.

Kannan, R. (1968). Some results on fixed points. Bulletin of Calcutta Mathematical Society 60: 71-76.

Kannan, R. (1969). Some results on fixed points- II. American Mathematical Monthly 76: 405-408.

Karapınar, E and Erhan, I.M. (2011). Best proximity point on different type contractions. Applied Mathematics and Information Sciences 3(3): 342-353.

Kirk, W.A., Srinivasan, P.S. and Veeramani, P. (2003). Fixed points for mappings satisfying cyclical contractive conditions. Fixed Point Theory 4 (1): 79-89.

Kikkawa, M and Suzuki T. (2008): Some similarity between contractions and Kannan mappings. Fixed Point Theory and Applications doi:10.1155/2008/649749.

Kohli, M., Shrivastava, R and Sharma, M. (2010). Some results on fixed point theorems in dislocated quasi metric space. International Journal of Theoretical and Applied Sciences 2: 27-28.

Kumari, P.S., Kumar, V.V and Sarma, I.R. (2012), Common fixed point theorems on weakly compatible maps on dislocated metric spaces. Mathematical Sciences 6: Article ID 71.

Panthi, D., Jha, K., Jha, P. K and Kumari, P. S. (2015). A Common Fixed Point Theorem for Two Pairs of Mappings in Dislocated Metric Space, American Journal of Computational Mathematics 5: 106-112.

Patel, S.T and Patel, M. (2013): Some results of fixed point theorem in dislocated quasi metric space. International Journal of Modern Engineering and Research Technology 1: 20-24.

Petric, M.A. (2010). Some results concerning cyclical contractive mappings. General Mathematics 18(4): $213-226$.

Rahman, M.U and Sarwar, M. (2014). Fixed point results in dislocated quasi metric spaces, International Mathematical Forum 9: 677-682.

Sarwar, M., Rahman, M. U and Ali, G. (2014). Some fixed point results in dislocated quasi metric spaces, Journal of Inequalities and Applications 278: 1-11.

Sessa, S. (1982). On a weak commutativity condition of mappings in fixed point considerations. Publications de l'Institut Mathématique 32(46): 149-153.

Wilson, W.A. (1931). On semi metric spaces. American Journal of Mathematics 53(2): 361-373.

Zeyada, F.M., Hassan G.H and Ahmad M.A. (2005). A generalization of fixed point theorem due to Hitzler and Seda in dislocated quasi metric space. Arabian Journal for Science and Engineering 31: 111-114.

Zoto, K., Houxha, E and Isufati, A. (2012). Some new results in dislocated and dislocated quasi metric space. Applied Mathematical Sciences 6: 3519-3526. 